\title{
Ontogenetic shifts in plant ecological strategies
}

\author{
Roberta L. C. Dayrell \\ André J. Arruda \\ Simon Pierce \\ Daniel Negreiros \\ Pablo B. Meyer \\ Hans Lambers \\ Fernando A. O. Silveira
}

First published: 25 September 2018

https://doi.org/10.1111/1365-2435.13221

Cited by: 1

\section{Abstract}

1. Ontogenetic shifts in plants are ubiquitous, but their ecological and evolutionary significance remain largely unknown. Juveniles have few opportunities to accumulate sufficient biomass to withstand damage, whereas adults allocate resources to reproduction. Thus, age-specific environmental filters are expected to drive selection towards specific resource-investment strategies for each developmental stage.

2. We tested whether species exhibited strategies that favour faster rates of biomass accumulation during early developmental stages to cope with vulnerability, shifting towards habitat-dependent strategies to optimise resource acquisition and use later on. We also hypothesised that juveniles exhibit greater intraspecific variability of strategies than adults, as a result of continuous filtering of traits throughout the plant's development towards adulthood.

3. We measured key leaf traits - leaf area (LA), leaf dry matter content (LDMC) and specific leaf area (SLA) - and calculated scores for competitor (C), stress-tolerator (S), ruderal (R) strategies of the CSR system for juveniles of 54 species and conspecific adults of 27 species naturally occurring either in unproductive (grassland) or productive (forest) habitats.

4. Juveniles exhibited higher SLA and LA and lower LDMC, and thus a more R-strategy in both habitats when compared with adults, but were not necessarily " $R$ " in absolute terms. We also found smaller intraspecific variation for the R-strategy in adults compared with juveniles in both habitats, whereas the variation of the other strategies was habitat dependent.

5. Ontogenetic shifts in ecological strategies appear to have been selected as a response to ontogeny-dependent filters. Thus, strategies that favour less costly leaves and faster growth rates (relatively R-selected) in juveniles shift towards $\mathrm{C}$ and/or $\mathrm{S}$ strategies in adulthood, depending on habitat productivity. Nevertheless, habitat-dependent specialisation seems to be a major driver of ecological strategy selection in juveniles. Our study reveals ontogeny-dependent strategies, offering a new approach to integrate plant development and functional specialisation. 


\section{INTRODUCTION}

Variability in many plant traits reflects underlying universal trade-offs in functioning that affect fitness, associated with environmental filtering, species distribution and community assembly (Díaz et al., 2016; Grime \& Pierce, 2012; Grime et al., 1997; Lambers \& Poorter, 1992; Reich, 2014; Wright et al., 2004). Viable trait combinations evident world-wide include, for example, large seeds on tall plants, but not large seeds on small plants (Díaz et al., 2016). Trait syndromes can thus be interpreted as "strategies" reflecting fitness, often considered equivalent to life histories.

While many definitions of "strategies" exist, Grime and Pierce (2012) emphasised the quantity of essential resources "acquired by an organism during its individual lifetime" and allocation between contrasting functions. However, this "lifetime allocation" view must be reconciled with the finding that resource allocation between functional traits changes during development (Mason, McGaughey, \& Donovan, 2013). Also, different developmental stages experience contrasting environmental filters and natural selection pressures (i.e., occupy different niches), which may explain changes in allocation patterns throughout programmed development (i.e., ontogeny; Lasky et al., 2015). Resource allocation depends not only on prevailing environmental conditions, but also on the inherent capacities of the plant - and these change over time as the plant accrues biomass, accumulates internal resources, and augments its acquisitive ability beyond the limited capacities of the initial seedling. Ontogeny likely changes the relative importance of different functional traits throughout the plant life span. Thus, a "strategy" can also be defined as an instantaneous process of resource allocation between competing functions, maximising fitness across contrasting niches during development. In other words, when the strategy is considered as an operating process for resource allocation, the apparent strategy can be expected to shift from seedling to mature stages: viable strategies may exhibit different ontogenetic trajectories for different species according to environment. Similar adult functioning may arise from seedlings with different traits.

To quantify ontogenetic shifts, strategies can be represented by suites of functional traits. Recent analyses of large trait databases demonstrate that small numbers of fundamental leaf traits - in particular specific leaf area (SLA; one-sided area of a fresh leaf divided by dry mass), leaf dry matter content (LDMC; dry mass of a leaf divided by water-saturated fresh mass) and leaf area (LA; one-sided area) - concisely represent the major axes of global plant functioning (resource economics and size; Pierce, Brusa, Vagge, \& Cerabolini, 2013; Pierce et al., 2017). Low values of SLA and high values of LDMC are associated with conservative growth, greater investment in leaf protection and increased leaf longevity, whereas the opposite holds for fast-growing species (Lambers \& Poorter, 1992). Leaf area largely determines capacity to intercept light, associated with competitive vigour, and constitutes a widely available indicator of the plant/organ size spectrum (Díaz et al., 2016).

Pierce et al. (2017) used global trade-offs in SLA, LDMC and LA to develop a strategy calculator tool (StrateFy) providing numerical quantification (scores) of the three primary strategies (competitor, C; stress-tolerator, S; ruderal, R) of CSR theory (Grime, 1977). Strategies represent adaptation to the intensity of environmental filters involving competition, abiotic limitation to growth (stress) and periodic biomass destruction (disturbance). C-selected "competitors" occupy stable, productive habitats with little disturbance, allocating resources to vegetative growth, large plant and organ size, thereby maximising resource acquisition. Sselected "stress-tolerators" survive in resource-poor or abiotically variable environments with 
low disturbance by allocating biomass to persistent tissues and mechanisms favouring resource conservation. R-selected "ruderal" species invest in rapid growth and completion of life cycle to avoid frequent lethal disturbance events, surviving in an inactive state as propagules. While much information can be gleaned from measurement of single traits, quantification of adaptive strategies integrates multiple traits, provides a theoretical (explanatory) background, and allows transferability of results and predictive power.

As strategies determine the suites of traits functioning in concert to affect fitness, their quantification provides an overall metric of plant functioning in the same way that "net photosynthetic rate" represents the sum of single traits such as $\mathrm{CO}_{2}$ uptake and respiration rates. Grime's system has proven useful to represent and compare functional strategies and community assembly across different ecological scales, from that of species (Pierce, Vagge, Brusa, \& Cerabolini, 2014), populations (May, Warner, \& Wingler, 2017), habitats (Negreiros, Le Stradic, Fernandes, \& Rennó, 2014; Rosado \& de Mattos, 2017), successional stages (Caccianiga, Luzzaro, Pierce, Ceriani, \& Cerabolini, 2006) and biomes (Pierce et al., 2017). The most recent, globally-calibrated, CSR analysis method (Pierce et al., 2017) is supported experimentally (Li \& Shipley, 2017). However, all previous investigation has involved adult plants, with no attempt to investigate whether CSR strategies change with ontogeny.

Plant ontogeny may be divided into sequential stages, from seed to senile (Gatsuk, Smirnova, Vorontzova, Zaugolnova, \& Zhukova, 1980), that interact differently with environmental factors and are subject to distinct sets of environmental filters (Grubb, 1977). Mounting evidence shows that environmental factors promote habitat specialisation, not only in adulthood, but also in early developmental stages (Metz, 2012; Poorter, 2007; Zalamea et al., $\underline{2016}$ ), indicating that natural selection plays a major role in the evolution of ontogenetic patterns, despite developmental constraints (Barton \& Boege, 2017). Ecological strategies are, therefore, expected to be habitat and stage specific (Grime \& Pierce, 2012), but it is not clear how these factors interact.

The susceptibility of seedlings to damage and stress is widely recognised across different vegetation types (Coelho, Capelo, \& Figueira, 2008; Moles \& Westoby, 2004; Stearns, 1976), being a major driver for the evolution of seed dormancy (Baskin \& Baskin, 2014). Although species that are S-selected as adults allocate resources to durable structures, their juveniles may not have sufficient biomass to produce structures that resist harsh environments (Coelho et al., 2008; Hallett, Standish, Jonson, \& Hobbs, 2014), and thus a different adaptive strategy could be evident in juveniles. Similarly, while species that are C-selected as adults invest in large leaves, their juveniles may invest either in less costly, short-lived leaves that enable faster growth rates, or in long-lived and well protected leaves that can resist damage caused by herbivores, pathogens and litterfall (Kitajima, Cordero, \& Wright, 2013; Poorter \& Bongers, 2006). However, adults must cope with the additional costs of reproduction (pollen, flowers, fruits, seeds) and efficiency in acquiring and using limiting resources can prove decisive for fitness (Cunningham, 1997; Stock, Pate, Kuo, \& Hansen, 1989). Thus, we expected mean CSR scores to reflect the greater vulnerability of juveniles and the high costs of maintenance and reproduction in adults.

Shifts in the strengths of ecological filters should affect not only the mean strategy, but also strategy variability (Jung, Violle, Mondy, Hoffmann, \& Muller, 2010). Intraspecific trait variability should be restricted when habitat filtering is stronger, reflecting niche width (Grime \& Pierce, 2012; Violle et al., 2012), and intraspecific variability of CSR scores can 
therefore be used to assess the width of viable ecological strategies of species (May et al., 2017; Pierce et al., 2013) and assess possible expansions or contractions in niche width during development. Specifically, because adult plants have undergone filtering across previous developmental stages (juvenile included), we expected adults to exhibit a smaller width of ecological strategies than juveniles, and for the extent to be habitat dependent.

Here, we aimed to investigate developmental shifts in plant ecological strategies by assessing the mean and the variability of CSR scores of species at two developmental stages. We compared juvenile and adult stages of species in two adjacent habitats with contrasting levels of productivity: a nutrient-impoverished grassland (unproductive habitat) and a forest (productive habitat). We tested predictions related to the following hypotheses (summarised in Figure 1): (a) the strategy signature of species tends to shift from ability to cope with high levels of disturbances (R-selected) in juveniles towards C- or S-selection in adults (in productive habitats and unproductive habitats, respectively); (b) the juvenile stage exhibits a larger width (greater variation) of CSR strategies than that of adults. We further explored adult and juvenile strategies evident between two adjacent habitats differing in productivity.

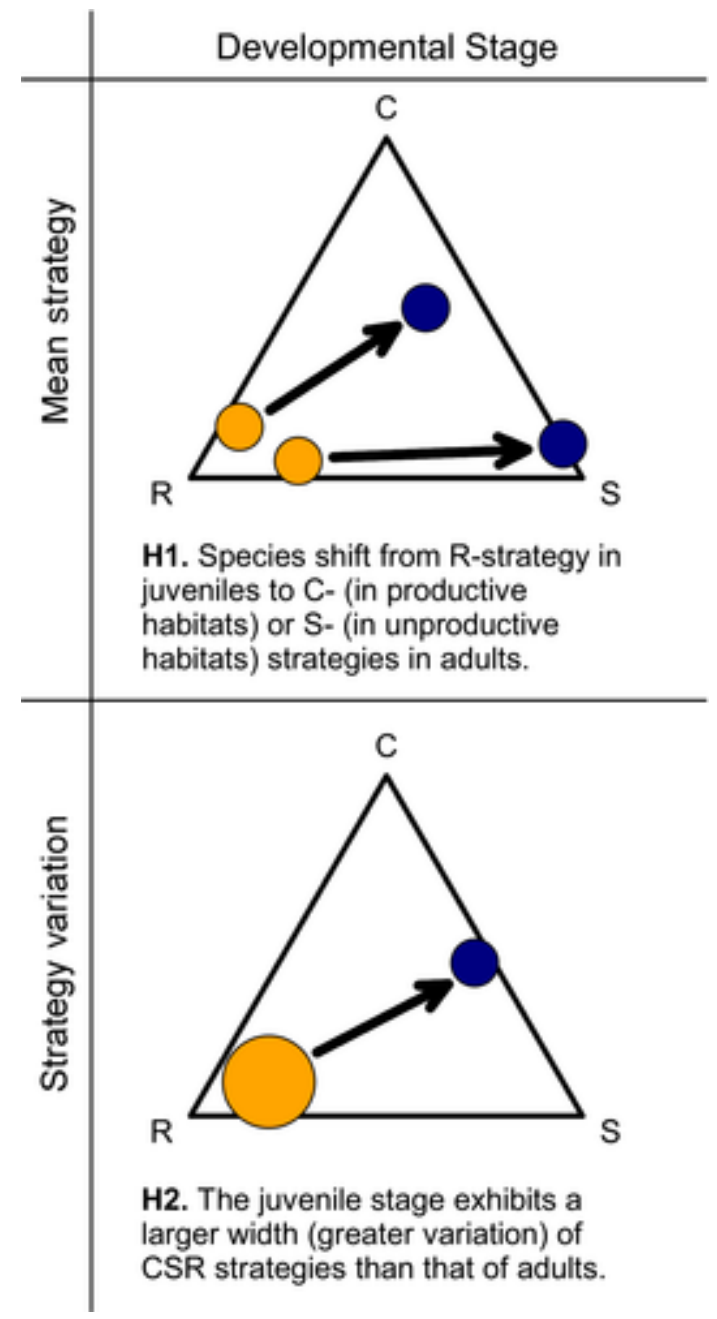

\section{Figure 1}

Hypotheses $(\mathrm{H})$ represented in ternary plots. Developmental stages: juveniles (orange) and adults (dark blue) 


\section{MATERIALS AND METHODS}

\subsection{Study area}

We measured functional traits in species from two neighbouring natural habitats with highly contrasting vegetation structure and composition at Serra do Cipó $\left(19^{\circ} 17^{\prime} \mathrm{S}, 43^{\circ} 35^{\prime} \mathrm{W}\right.$, approximate altitude of 1,200 $\mathrm{m}$ a.s.1.), Southeast Brazil. The study site is part of the geographic barrier that represents an ecotone between two global biodiversity hotspots, the Cerrado and the Atlantic Rainforest ecoregions. The climatic regime in the region is characterised by dry winters and rainy summers (Brito et al., 2017). We studied the two main mountain top vegetation types: a grassland (known as campo rupestre) and a forest (Supporting Information Appendix S1).

The campo rupestre is a megadiverse mosaic of grasslands associated with rocky outcrops which occurs on severely P-impoverished, shallow, acidic and well-drained quartzite-derived soils (Oliveira et al., 2015). Campo rupestre species often experience strong winds, seasonal fires and water shortage, large fluctuations in daily temperature and high irradiance (Silveira et al., 2016) which results in a clear dominance of the stress-tolerant strategy (Negreiros et al., 2014).

Patches of gallery forest and hilltop forest occur within the campo rupestre matrix (Coelho, Carlos, et al., 2018). These forests occur at moist locations, associated with springs and streams or with deeper soil patches that are less well drained than the surrounding grasslands (Coelho et al., 2016; Valente, 2009). Here, plants experience a range of milder environmental conditions compared with the grassland habitat, for example, slightly less nutrient-poor soils and historically lower fire frequency (Coelho, Neves, Perillo, Morellato, \& Fernandes, 2018; Valente, 2009).

\subsection{Ontogenetic stages and species selection}

We contrasted functional traits and ecological strategies of juvenile and adult stages. Juveniles were defined as structurally simple individuals with an unbranched shoot, mature leaves, no signs of resprouts or clonal origin (to make sure they represented individual genets) and absence of reproductive organs (Gatsuk et al., 1980). Since a few species demonstrated embryonic structures such as persistent cotyledons, our definition comprises both seedling and juvenile states (sensu Gatsuk et al., 1980). The average height of juvenile individuals sampled in the grassland was $38 \pm 28 \mathrm{~mm}$ (mean $\pm S D$, range $3-145 \mathrm{~mm}, n=212)$ and in the forest $58 \pm 27 \mathrm{~mm}$ (range $9-153 \mathrm{~mm}, n=195$ ).

To compare the ontogenetic shifts in leaf traits and CSR strategies among contrasting habitats, we sampled five sites of grassland and five sites of forest to search for juveniles, and selected species whenever we found at least six juvenile individuals to serve as replicates. Since the low density of juveniles strongly limited availability of samples in both habitats, our selection criteria reflected local abundance of juveniles.

In order to compare developmental stages, we also targeted conspecific adults whenever it was possible to sample at least six individuals in the area where juveniles were sampled. Altogether, we measured functional traits in juveniles of 27 species from grassland, and 27 from forest, and adults of 20 species from grassland and seven from forest. Campo rupestre 
species often have very narrow geographic ranges and patchy distributions (Echternacht, Sano, Trovó, \& Dubuisson, 2011), and it is possible to find many conspecific adults at the same site. However, the forest species do not present the same pattern, and very few species had at least six individuals within our sampling area, which incurred a smaller sample size for forest adults. Juveniles of just one species were found in both habitats during our sampling efforts (Supporting Information Appendix $\underline{\text { S2}}$-Table $\underline{\text { 11) }}$.

\subsection{Functional traits and CSR classification}

Leaf area, LDMC and SLA measurements were determined according to Pérez-Harguindeguy et al. (2013) from February to early April 2016, mid and late rainy season, when leaves are fully expanded and mature, and juvenile survival is not compromised by the seasonal drought. We collected juveniles (whole individuals) and branches from adults. Samples were immediately saturated using a spray bottle, placed in moist paper bags, sealed in plastic bags and kept in a cooler until placed in a refrigerator for periods of 12 to $24 \mathrm{hr}$ at $4{ }^{\circ} \mathrm{C}$ (PérezHarguindeguy et al., 2013). Measurements were taken from two to eight undamaged, fully expanded leaves (including the petiole) per individual. We scanned leaves and used Leaf Area Measurement (LAM v1.3 by Andrew Askew;

www.nucleodiversus.org/uploads/file/leafarea.zip) to determine LA. We used an analytic scale (precision of $0.01 \mathrm{mg}$ ) to obtain leaf fresh weight (from turgid leaves) and leaf dry weight (after leaves had dried to constant weight in an oven at $60^{\circ} \mathrm{C}$ ).

Leaf area, SLA and LDMC values were entered into "StrateFy" (Pierce et al., 2017; available at https://doi.org/10.1111/1365-2435.12722) to calculate C-, S- and R-selection scores for each individual. Briefly, Pierce et al. (2017) calibrated the CSR tool using data for 3,068 species obtained from a global database by: (a) performing a principal component analysis (PCA) of the three key leaf traits (LA, LDMC and SLA); (b) regressing trait values against PCA axes; and (c) using these regression equations to produce a Microsoft Excel spreadsheet. This spreadsheet then uses the regression equations to compare any trait values entered against the global trade-off among these traits. Extremely high values of SLA and LDMC are representative of extremes of fast and slow leaf economics, respectively. Leaf area is correlated with seed and whole plant size traits in a spectrum running orthogonal to the economics spectrum, and is also a fundamental determinant of the ability of species to intercept light (Díaz et al., 2016; Pierce et al., 2013). The CSR classification method does not use each trait to directly represent the extent of C, S and R-selection: it is the trade-off between them, integrated and compared against trade-offs evident globally, from which CSR scores are calculated (Pierce et al., 2017). Thus, although only three traits are measured, they represent a wider range of plant functioning. Indeed, co-inertia analysis demonstrates that this method can represent variation in 14 key leaf, reproductive and whole plant functional traits, including leaf nitrogen concentration, seed mass and flowering phenology (Pierce et al., 2017). The method has been tested and supported experimentally (Li \& Shipley, 2017).

\subsection{Data analyses}

In order to assess ontogenetic shifts and functional specialisation in juveniles, we tested whether developmental stages from both habitats exhibited different leaf trait values (SLA, LDMC and log-transformed LA) and CSR scores using linear mixed-effect models-LMMs (Pinheiro \& Bates, 2000). These models contained fixed effects for developmental stages, habitat and their interaction, and random effects for plant species nested within location to avoid pseudo-replication. Significance was estimated by comparing a minimal model with the 
null model. The minimal adequate models were obtained by a stepwise deletion of nonsignificant parameters and their interaction, starting from a full factorial model $(p>0.05)$. For each model, residuals were visually inspected for heteroscedasticity. In the presence of heteroscedasticity, the variance structure of the data was modelled, with the best variance structure determined by comparing AICc and standardised residual plots (Zuur, Ieno, Walker, Saveliev, \& Smith, 2009). The LMMs were performed using the "lme" function, and the variance structure of the data was modelled using the "weights" option within the "nlme" package (Pinheiro et al., 2017). The "effects" package (Fox, 2003) was used for further inspection of means and $95 \%$ confidence intervals (CI) to identify significant differences between developmental stages and habitats.

Since a complete control for phylogenetic effects between habitats during species selection was not possible, we examined phylogenetic signal in leaf trait values to account for possible confounding effects of habitat and phylogeny. Briefly, species relationships were reconstructed using "Phylomatic" (http://phylodiversity.net/phylomatic/), topology was corrected and improved manually in "Mesquite" (http://mesquiteproject.org/) based on a number of recent studies of molecular phylogeny. To estimate branch lengths (i.e., time since divergence), we dated nodes according to previous studies (Supporting Information Appendix $\underline{\text { S3}}$ ) and positioned undated nodes evenly in the tree with the "bladj" algorithm of Phylocom software (Webb, Ackerly, \& Kembel, 2008). We then examined a phylogenetic signal in LDMC and log-transformed SLA and LA separately for adults and juveniles, using the Blomberg's $K$ test with 100,000 randomisations (Blomberg, Garland, \& Ives, 2003; Münkemüller et al., 2012) in the "picante" package (Kembel et al., 2010).

We tested if the multivariate structure provided by LA, LDMC and SLA could effectively distinguish ontogeny- and habitat-related functional differences. First, trait values of each species at each developmental stage were log-transformed to provide distributions as close as possible to normality prior to PCA. A PCA of LA, LDMC and SLA values was then performed using the "principal" function, and varimax rotation was applied to the first two axes within the "psych" package (Revelle, 2017). We used LMMs as described above to assess differences in rotated components (PC1 and PC2) between groups.

Finally, in order to assess ontogeny- and habitat-related shifts in the width of ecological strategies, we developed a novel approach that uses the standard deviation $(S D)$ of C-, S- and $\mathrm{R}$ - scores of each species at each developmental stage as a measurement of variation in functional strategies within groups of adults or juveniles of each species. A higher $S D$ in CSR scores indicates a broader range of strategies, whereas a lower $S D$ indicates a smaller strategy width. Paired tests were used to compare developmental stages and unpaired test was used to compare juvenile plants from the two habitats. The nonparametric paired Wilcoxon rank sum test was used to assess differences between groups.

All analyses were performed in the R environment ( $R$ Development Core Team, 2017) and graphs created with "ggplot2" package (Wickham, 2016). The relative contribution of the three CSR dimensions was represented in ternary plots, with each coordinate varying from $0 \%$ to $100 \%$, using the "ggtern" package (Hamilton, 2017). We used the mean of trait values, PCA scores and C-, S- and R-scores for each species at each developmental stage for all figures. 


\section{RESULTS}

Juveniles from both grassland and forest showed relatively acquisitive leaf economics trait values (higher SLA and lower LDMC; Figure $2 \mathrm{a}, \mathrm{b}$ ), and smaller leaves than adults (Figure $\underline{2}$ c; Supporting Information Appendix $\underline{\mathrm{S} 2}-\mathrm{Table} \underline{\mathrm{S} 2}$ ). Distinct leaf trait patterns were also observed for contrasting habitats, as forest juveniles had higher SLA and larger leaves than grassland species (Figure $2 \mathrm{a}, \mathrm{c}$ ), but there was no significant difference in LDMC (Figure $2 \mathrm{~b}$ ). The full model including developmental stage, habitat and their interaction best explained LA and SLA values, whereas the final model for LDMC included only developmental stage (Table 1). The multivariate structure provided by our data clearly separated ontogeny- and habitat-related functional differences (Figure 2d; Table 1; Supporting Information Appendix

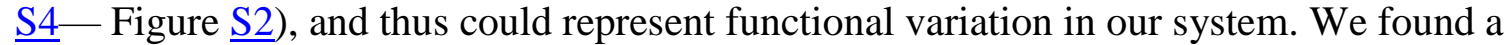
weak phylogenetic signal only in the LA of juveniles $(K=0.607 ; p=0.001)$, and no significant signal for the other two traits or LA of adults (Supporting Information Appendix $\underline{\text { S4-Table } \underline{\mathrm{S}} \text { ). }}$.
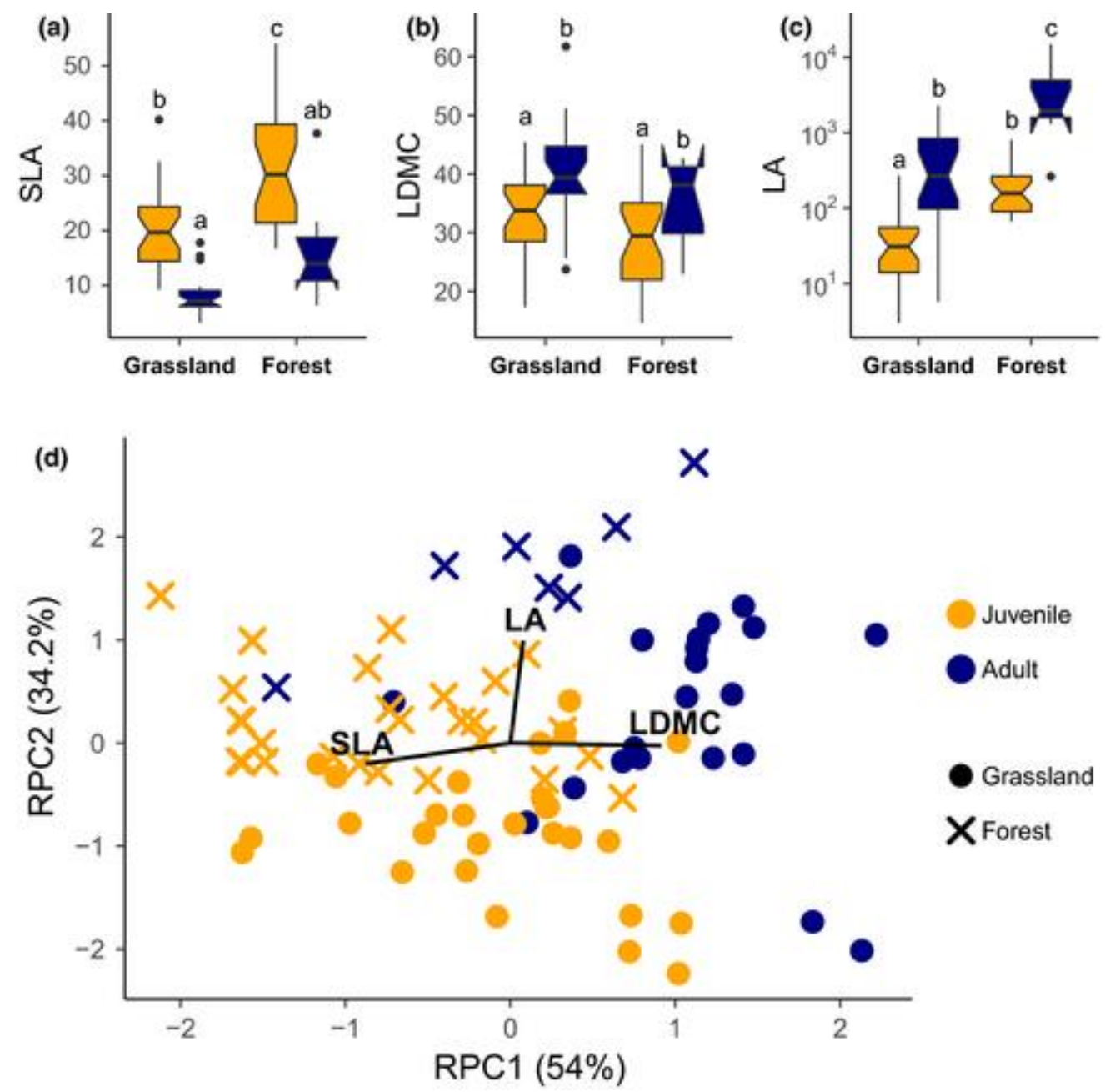

Figure 2

Ontogenetic shifts in leaf traits of juveniles and adults from contrasting habitats in a forestgrassland boundary in Southeast Brazil. Comparisons of functional trait values between habitat and developmental stages of: (a) specific leaf area (SLA; $\mathrm{mm}^{2} / \mathrm{mg}$ ), (b) leaf dry matter content (LDMC; \%) and (c) leaf area (LA; $\mathrm{mm}^{2}$ ). Boxplots show medians (horizontal lines) with quartiles (box margins), the lowest and the highest values within 1.5-interquartile range (whiskers) and outliers (filled circles). Within each individual plot, different letters indicate 
significant differences between trait values based on 95\% confidence intervals. (d) Principal component analysis of trait variation for adults and juveniles of plant species from grassland and neighbouring forest. The percentage of variation explained by PCA-rotated component 1 (PC1) and PCA-rotated component 2 (PC2) is shown in parentheses

Table 1. Results of a linear mixed-effect model testing the effect of developmental stage and habitat type on specific leaf area (SLA), leaf dry matter content (LDMC), log-transformed leaf area (LA), PCA scores — rotated component 1 (PC1) and PCA-rotated component 2 (PC2) and C-, S- and R-scores in plants from Southeast Brazil

\begin{tabular}{|c|c|c|c|c|c|c|c|}
\hline Data & $\begin{array}{l}\text { Model } \\
\text { ID }\end{array}$ & Model & $K$ & $\log L$ & AICc & $\triangle \mathrm{AICc}$ & $P$ \\
\hline \multirow[t]{2}{*}{$\begin{array}{l}\text { SLA } \\
\left(\mathrm{mm}^{2} / \mathrm{mg}\right)\end{array}$} & $\mathrm{MM}$ & $\begin{array}{l}\text { SLA stage } * \\
\text { habitat, } \\
\text { random = species }\end{array}$ & 11 & -1765.01 & 3552.49 & -655.03 & $<0.0001$ \\
\hline & null & $\begin{array}{l}\text { SLA } \sim 1, \\
\text { random = species }\end{array}$ & 4 & -2099.73 & 4207.52 & - & - \\
\hline \multirow[t]{2}{*}{$\begin{array}{l}\text { LDMC } \\
(\%)\end{array}$} & $\mathrm{MM}$ & $\begin{array}{l}\text { LDMC } \sim \text { stage } \\
\text { random }=\text { species }\end{array}$ & 6 & -1735.58 & 3483.30 & -239.13 & $<0.0001$ \\
\hline & null & $\begin{array}{l}\mathrm{LDMC} \sim 1, \\
\text { random }=\text { species }\end{array}$ & 4 & -1857.18 & 3722.43 & - & - \\
\hline \multirow[t]{2}{*}{$\begin{array}{l}\log \mathrm{LA} \\
\left(\mathrm{mm}^{2}\right)\end{array}$} & MM & $\begin{array}{l}\operatorname{logLA} \sim \text { stage } * \\
\text { habitat, } \\
\text { random = species }\end{array}$ & 11 & -156.71 & 335.89 & -640.43 & $<0.0001$ \\
\hline & null & $\begin{array}{l}\operatorname{logLA} \sim 1, \\
\text { random }=\text { species }\end{array}$ & 4 & -484.12 & 976.32 & - & - \\
\hline \multirow[t]{2}{*}{ PC1 (\%) } & $\mathrm{MM}$ & $\begin{array}{l}\text { PC1 stage } * \\
\text { habitat, } \\
\text { random = species }\end{array}$ & 10 & -373.51 & 767.41 & 415.47 & $<0.0001$ \\
\hline & null & $\begin{array}{l}\mathrm{LA} \sim 1, \\
\text { random = species }\end{array}$ & 4 & -587.40 & 1182.88 & - & - \\
\hline \multirow[t]{2}{*}{ PC2 (\%) } & $\mathrm{MM}$ & $\begin{array}{l}\text { PC2 stage } * \\
\text { habitat, } \\
\text { random = species }\end{array}$ & 10 & -336.44 & 693.27 & 604.49 & $<0.0001$ \\
\hline & null & $\begin{array}{l}\mathrm{LA} \sim 1, \\
\text { random = species }\end{array}$ & 4 & -644.84 & 1297.76 & - & - \\
\hline \multirow[t]{2}{*}{$\mathrm{C}(\%)$} & $\mathrm{MM}$ & $\begin{array}{l}\mathrm{C} \sim \text { stage } * \text { habitat } \\
\text { random = species }\end{array}$ & 10 & -1718.22 & 3456.83 & -819.65 & $<0.0001$ \\
\hline & null & $\begin{array}{l}\mathrm{C} \sim 1, \\
\text { random = species }\end{array}$ & 4 & -2134.20 & 4276.48 & - & - \\
\hline \multirow[t]{2}{*}{$\mathrm{S}(\%)$} & MM & $\begin{array}{l}\mathrm{S} \sim \text { stage } * \text { habitat } \\
\text { random = species }\end{array}$ & 11 & -2209.82 & 4442.11 & -316.59 & $<0.0001$ \\
\hline & null & $\begin{array}{l}\mathrm{S} \sim 1, \\
\text { random = species }\end{array}$ & 4 & -2375.32 & 4758.70 & - & - \\
\hline \multirow[t]{2}{*}{$\mathrm{R}(\%)$} & $\mathrm{MM}$ & $\begin{array}{l}\mathrm{R} \sim \text { stage }+ \text { habitat } \\
\text { random = species }\end{array}$ & 7 & -2291.08 & 4626.66 & -453.32 & $<0.0001$ \\
\hline & null & $\begin{array}{l}\mathrm{R} \sim 1, \\
\text { random = species }\end{array}$ & 4 & -2520.80 & 5049.60 & - & - \\
\hline
\end{tabular}

\section{Note}


- Random intercepts per species were specified in the model. Significance was estimated by comparing minimal model (MM) with the null model (null). The Akaike's information criterion with a correction for finite sample sizes (AICc) represents the uncertainty of the model whereby lower AICc values represent the more parsimonious models. $\triangle$ AICc is the difference in AICc values between minimal and null models, $\log \mathrm{L}$ is the $\log$-likelihood and $K$ is the number of parameters in each model. Significant P-values $(p<0.05)$ are shown in bold.

Juveniles from the grassland were mainly concentrated around the S/SR region of the triangle (mean C:S:R strategy = 2:64:34\%; Figure $3 \mathrm{a}, \mathrm{c}, \mathrm{d}$ ), whereas adults were mainly S (13:83:4\%; Figure $\underline{3} \mathrm{a}, \mathrm{d})$. Juveniles from the forest exhibited a mean strategy of S/R (9:44:47\%; Figure $\underline{3} b, c, d)$ and adults exhibited a mean strategy of C/S (34.6:48.8:16.6\%; Figure $\underline{3} b, d)$.
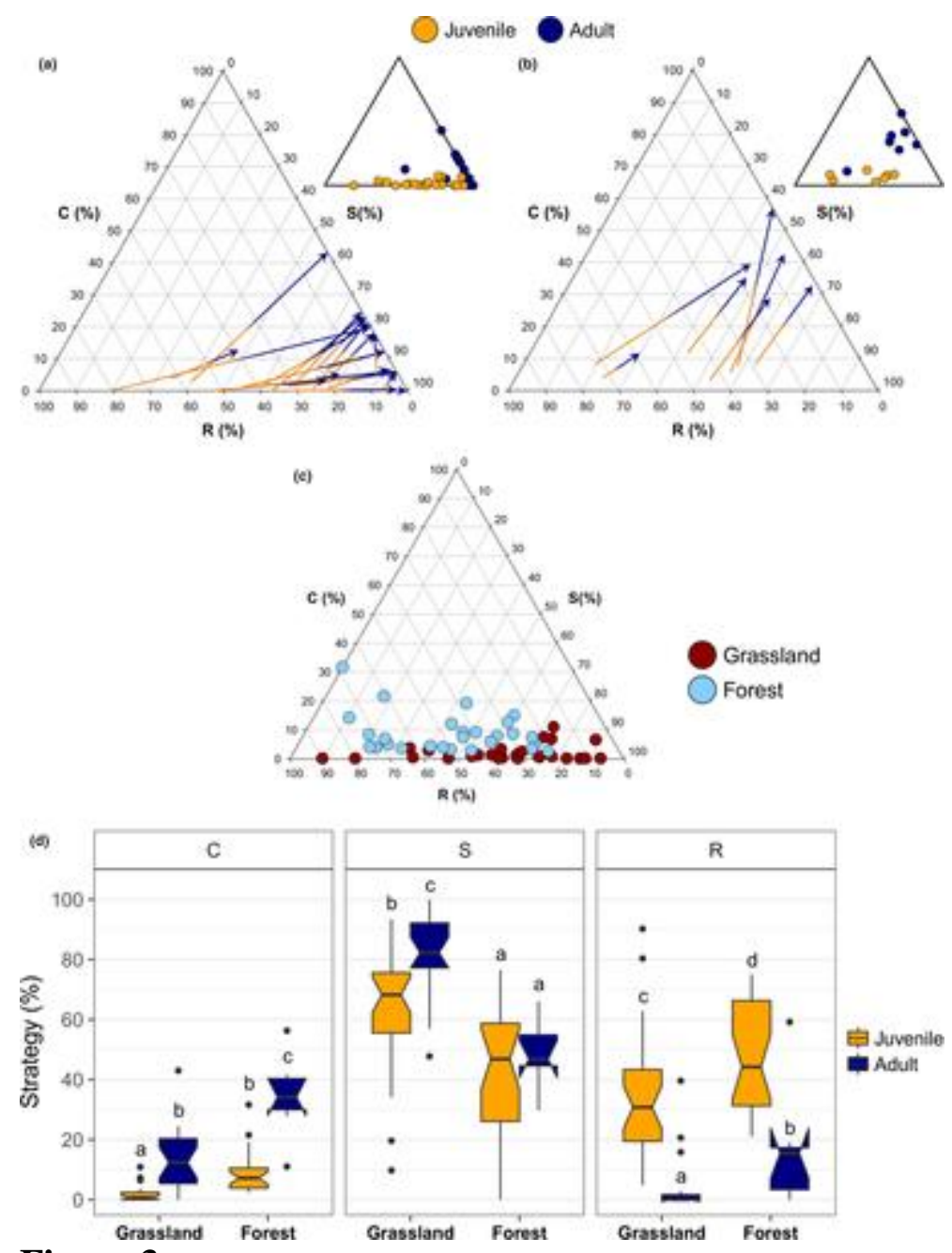

Figure 3

Ontogenetic shifts in CSR strategies in grassland and forest habitats in Southeast Brazil. Shifts in the relative proportion of C-, S- and R-selection represented by the direction of arrows in the ternary plot (juvenile species = orange end of arrows; conspecific adults $=$ dark blue end) for plant species from: (a) grassland and (b) forest; small insets in (a) and (b) show the relative proportion of C-, S- and R-selection for each plant species from each habitat. (c) The relative proportion C-, S- and R-selection represented in a ternary plot for juveniles from grassland (red) and forest (light blue). (d) Comparison of C-, S- and R-scores between habitat and developmental stages. Within each individual panel, different letters indicate significant 
differences between scores based on $95 \%$ confidence intervals from linear mixed-effect models (Table 1 )

Ontogenetic shifts in ecological strategies were significant for all strategies from both habitats, except for the S-selection in forest species (Figure $\underline{3} a, b$, d; Table $\underline{1}$; Supporting Information Appendix S5). In the grassland, juvenile-to-adult shifts were characterised mainly by changes from R- towards C- and S-strategies (Figure $\underline{3} \mathrm{~d}$ ). In forest species, ontogenetic shifts were represented by changes from R- towards C-selection (Figure $\underline{3} \mathrm{~d}$ ). Juveniles from the contrasting habitats also exhibited different ecological strategies, as forest juveniles had a higher $\mathrm{C}$ - and R-score, and grassland juveniles showed a higher S-score (Figure $\underline{3} \mathrm{c}, \mathrm{d}$ ). The full model including developmental stage, habitat and their interaction best explained $\mathrm{C}$ - and $\mathrm{S}$-selection. The final model for R-selection included developmental stage and habitat, but not the effect of their interaction which shows that the magnitude of the ontogenetic shifts away from R-selection was habitat-independent (Table $\underline{1}$ ).

Ecological strategy width was habitat and ontogeny dependent. In grassland, $S D$ in S- and Rscores of juveniles was eight and 25 times greater, respectively, and C-score was a third of that of adults (Figure $\underline{4} \mathrm{a}$; Supporting Information Appendix $\underline{\mathrm{S} 4}-$ Table $\underline{\mathrm{S} 5}$ ). The R-strategy $S D$ was four times greater for juveniles in the forest compared with that of adults, but $S D$ of $\mathrm{C}$ - and S-selection was not significantly different (Figure $4 \mathrm{~b}$; Supporting Information Appendix $\underline{\mathrm{S} 4}$-Table $\underline{\mathrm{S} 5}$ ).
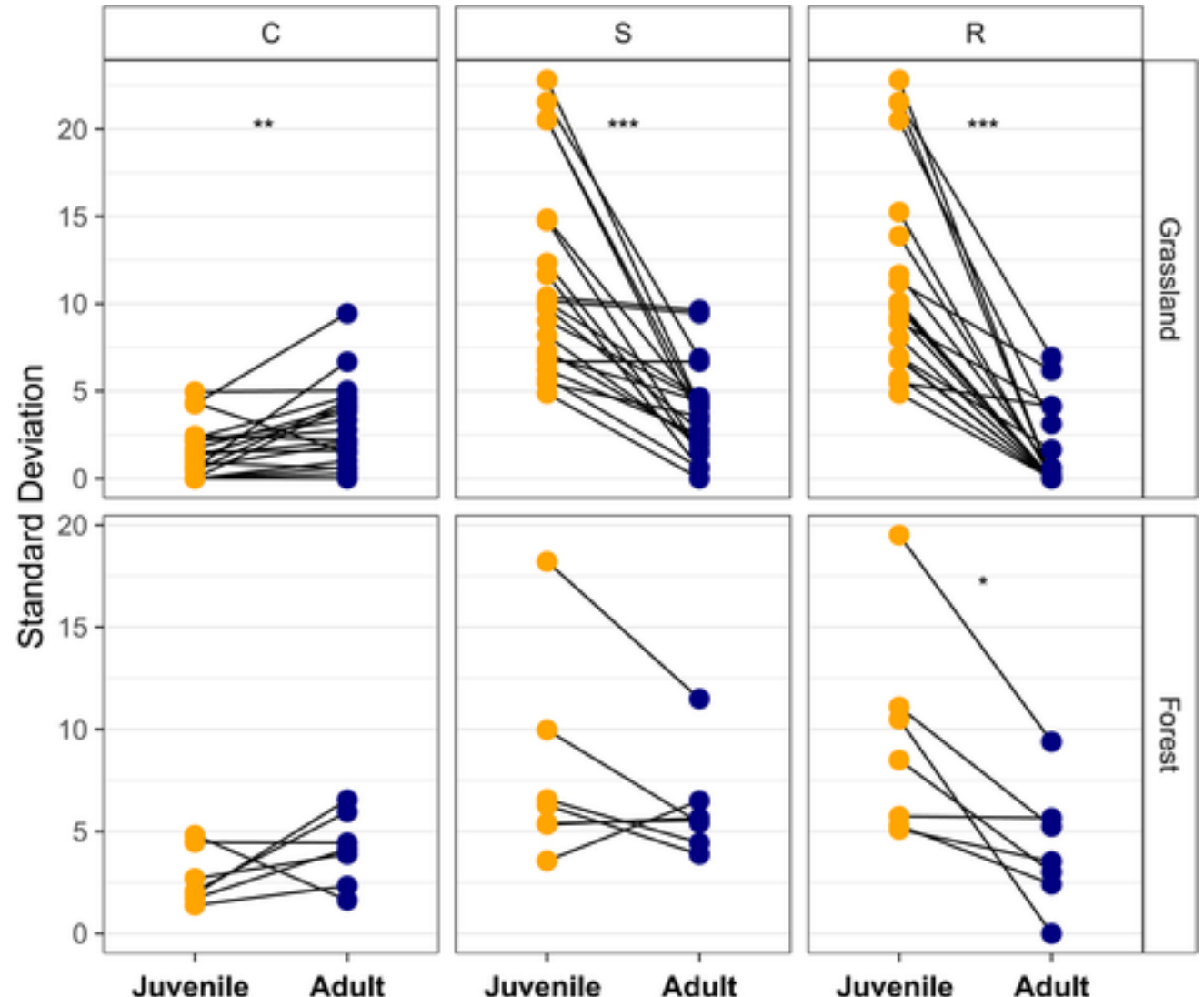

\section{Figure 4}

Variation in CSR strategies between juveniles and adults. Standard deviation $(S D)$ in C-, Sand R-scores compared between juveniles (orange) and adults (dark blue) for grassland and forest habitats separately. The lines connect $S D$ values of conspecific juveniles and adults. 
*Denotes significance at the $p<0.05, * * p<0.01, * * * p<0.001$ level (Supporting Information

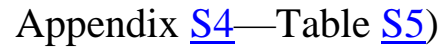

\section{DISCUSSION}

Despite the recent progress in trait-based plant ecology, plant regeneration traits remain poorly understood (Larson \& Funk, 2016), and this limits our knowledge of the assembly of natural and managed communities (Grubb, 1977; Paine et al., 2015). Our study shows ubiquitous ontogenetic shifts in plant ecological strategies amongst species, thereby suggesting the need to integrate plant development with functional specialisation to better predict assembly patterns and responses of plant communities to environmental changes (Larson \& Funk, 2016). As we predicted, plants from both habitats exhibited strategies tending towards the R-strategy in the juvenile stage, and shifts of a similar magnitude away from the R-strategy into adulthood, possibly due to the greater vulnerability of early developmental stages to damage (Harms \& Dalling, 1997; Moles \& Westoby, 2004). Adults also showed smaller intraspecific variability for the R-strategy than juveniles, indicating that adults from both habitats are strongly filtered against this strategy towards more conservative and/or competitive strategies. However, contrary to our expectations, in absolute terms the ecological strategies of juveniles were not strongly R-selected (although juveniles tended to be relatively R-selected when compared with adults, few were "ruderal" per se). R- and Sstrategies were equally represented in forest juveniles, whereas the S-strategy prevailed in grassland juveniles. We also found significant differences in mean strategies of juveniles between the two habitats which indicates that habitat filtering takes place during early developmental stages (Metz, 2012; Poorter, 2007). Altogether, our results suggest that despite the remarkable ontogenetic shifts in ecological strategies, a functional habitat-dependent specialisation is the main driver of selection for ecological strategy in juveniles.

According to CSR theory (Grime, 1977) and its underlying premise of trade-offs in resource allocation (Lambers \& Poorter, 1992; Lambers, Poorter, \& Van Vuuren, 1998), the increased selection away from $\mathrm{R}$ in adults relative to juveniles suggests a greater investment in growth rate during early stages of development as a habitat-independent strategy to cope with higher levels of disturbance. A strategy to accumulate biomass faster in juveniles should improve plant fitness if it enhances the chances of an individual reaching a functionally specialised stage that is less susceptible to disturbances such as fire and herbivory (Bond, 2000). However, our results show a large contribution of S-selection to the juvenile mean strategy, suggesting that juveniles from both habitats are slow-growing. We found that stress is the prevailing filter for plants in grassland, regardless of their developmental stage, possibly because even juveniles from unproductive habitats can be resistant to harsh conditions such as water deficit and nutrient deficiency (Milberg \& Lamont, 1997; Negreiros, Fernandes, Efremova, Le Stradic, \& Neves, 2016; but see Coelho et al., 2008). In the forest, juvenile mean strategy had similar contributions from S- and R-components which seems to represent the mid-point in a spectrum of microhabitat specialists, ranging from gap (poorly-defended fast-growing) to understorey (well-defended slow-growing) species (Kitajima et al., 2013; Poorter \& Bongers, 2006). Therefore, during early developmental stages, plants invest in strategies that favour faster rates of biomass accumulation than adults do, but can still remain at the "slow" or conservative extreme of the plant economics spectrum (Reich, 2014) due to habitat filtering.

Recent developments in trait-based community ecology have highlighted the importance of intraspecific variation in understanding community structure and ecosystem functioning 
(Violle et al., 2012). Ontogenetic changes are regarded as a major source of variation between conspecifics (González-Varo \& Traveset, 2016), but it is rarely assessed whether trait variability itself increases or decreases during development. Here, we used the $S D$ of CSR scores to test our second hypothesis that variability in ecological strategies is lower in adults as a result of continuous filtering throughout ontogeny. We found that adults exhibited a much smaller $S D$ for the R-strategy than their conspecific juveniles. This, together with their overall low mean R-scores, indicates that adults are strongly filtered against the R-strategy during development. As less investment in one particular CSR component implies greater investment in another (Grime \& Pierce, 2012), our results suggest a stronger habitat filtering in adulthood towards strategies of resource allocation towards competition and/or stress-tolerance (Negreiros et al., 2014; Pierce et al., 2017), possibly due to the high costs imposed by reproduction activities in this later stage (Oñate \& Munné-Bosch, 2009; Thomas, 2011). We also found an intricate pattern for the $S D$ of C- and S-scores, which were habitat- and ontogeny-dependent, further indicating that ontogenetic shifts in plant strategies are mainly driven by changes in the intensity of the disturbance filter.

We show that the CSR framework provided additional information useful to assess the functional ecology of the regeneration niche than trait analyses alone. Indeed, juveniles exhibited relatively acquisitive leaf economics and smaller leaves than adults, confirming previous studies (Ishida, Yazaki, \& Hoe, 2005; Mason et al., 2013). However, measuring functional traits alone could not have revealed differences in ontogenetic shifts between habitats, since the exact same pattern - that is, decrease in SLA, and increase in LDMC and LA from juveniles to adults - was observed for both habitats when only trait analyses were performed. Divergent ontogenetic shifts towards different ecological strategies in each habitat only emerged when plants were arranged according to the fundamental trade-offs described by CSR theory. We argue that investigating the ontogenetic shifts in the context of CSR theory (Grime, 1977), combined with a careful analysis of the ecological and physiological significance of SLA, LDMC (Lambers \& Poorter, 1992; Lambers et al., 1998) and leaf size (Cornelissen, 1999; Givnish, 1987; Parkhurst \& Loucks, 1972), has brought fresh perspectives that were not captured by previous trait analyses, offering an explanation for why the ontogenetic shifts occur, and allowing the processes reported here to be compared with other settings.

Although previous studies have reported phylogenetic nonindependence in leaf traits (Mason, Goolsby, Humphreys, \& Donovan, 2016), we only found a weak significant phylogenetic signal for LA of juveniles in our dataset. Since juveniles of 15 (out of 29) grassland species and 19 (out of 21) forest species belong to families sampled in both habitats, and our samples involved 19 plant families, phylogenetic effects are unlikely to play a role in the observed patterns.

In conclusion, we present the first quantitative assessment of development-related shifts in plant ecological strategies. Our results show that early stages of development exhibit a relatively acquisitive strategy that favours faster biomass accumulation, and then shifts towards more conservative and/or competitive strategies at a later stage, depending on habitat. However, juveniles were not necessarily "ruderal" in absolute terms, exhibiting functional habitat-related specialisation, which suggests that habitat conditions play a major role in driving strategies, starting at early stages of development. We found that ontogenetic shifts in the width of ecological strategies were habitat dependent, but that adults were strongly filtered against the R-strategy, towards strategies that optimise resource acquisition and use in their habitats. Our approach unveiled potentially general relationships between strategies, 
developmental stages and the environment, and provides an opportunity to further understand community assembly and the importance of functional specialisations during different stages of the plant life cycle. Finally, we contend that the ecology and evolution of plant strategies cannot be fully appreciated without integrating the full spectrum of functional ontogenydependent traits.

\section{ACKNOWLEDGEMENTS}

We thank GM Brandão, EE Serra Morena, GW Fernandes and PN Serra do Cipó for logistic support, GW Fernandes, QS Garcia and LV Modolo for laboratory equipment, TJ Guerra, JEC Figueira, CM Jacobi, RS Oliveira, RRC Solar and three anonymous reviewers for comments on earlier versions of the manuscript, JVS Messeder for fieldwork and laboratory assistance and LF Fuzessy, CG Pereira and M Renton for statistical advice. R.L.C.D. and A.J.A. received scholarships from CAPES. R.L.C.D. received a Scholarship for International Research Fees at UWA. F.A.O.S. receives research productivity grants from CNPq. CAPES PVE program (88881.068071/2014-01) provided a fellowship to H.L. Financial support was provided by CAPES, CNPq and FAPEMIG. We declare that there is no conflict of interest.

\section{AUTHORS' CONTRIBUTIONS}

R.L.C.D. and F.A.O.S. conceived the idea, with inputs from S.P. R.L.C.D. and A.J.A. designed and conducted fieldwork. P.B.M. identified the species. R.L.C.D., D.N. and S.P. analysed the data. R.L.D.C. led the writing of the manuscript. F.A.O.S., S.P., D.N. and H.L. provided critical feedback to data interpretation and drafting of the manuscript. All authors made intellectual contributions and provided essential feedback.

\section{DATA ACCESSIBILITY}

Data from this manuscript are publicly available at Figshare Repository https://doi.org/10.6084/m9.figshare.7097969 (Dayrell et al., 2018).

\section{REFERENCES}

- Barton, K. E., \& Boege, K. ( 2017). Future directions in the ontogeny of plant defence: Understanding the evolutionary causes and consequences. Ecology Letters, 20, 403411. https://doi.org/10.1111/ele.12744.

$\underline{\text { Wiley Online Library PubMed Web of Science®Google Scholar }}$

- Baskin, C. C., \& Baskin, J. M. ( 2014). Seeds: Ecology, biogeography, and evolution of dormancy and germination ( 2nd ed.). San Diego: Elsevier Science.

$\underline{\text { Google Scholar }}$ 
- Blomberg, S. P., Garland, T., \& Ives, A. R. ( 2003). Testing for phylogenetic signal in comparative data: Behavioral traits are more labile. Evolution, 57, 717- 745. https://doi.org/10.1111/j.0014-3820.2003.tb00285.x.

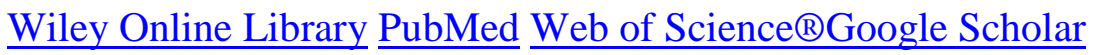

- Bond, B. J. ( 2000). Age-related changes in photosynthesis of woody plants. Trends in Plant Science, 5, 349- 353. https://doi.org/10.1016/S1360-1385(00)01691-5.

$\underline{\text { Crossref }} \underline{\text { CAS PubMed }} \underline{\text { Web of Science } ® \text { Google Scholar }}$

- Brito, V. L. G., Maia, F. R., Silveira, F. A. O., Fracasso, C. M., Lemos-Filho, J. P., Fernandes, G. W., ... Staggemeier, V. G. ( 2017). Reproductive phenology of Melastomataceae species with contrasting reproductive systems: Contemporary and historical drivers. Plant Biology, 19, 806-817. https://doi.org/10.1111/plb.12591.

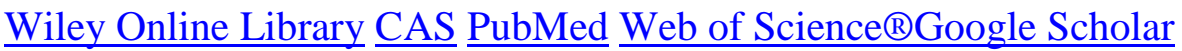

- Caccianiga, M., Luzzaro, A., Pierce, S., Ceriani, R. M., \& Cerabolini, B. ( 2006). The functional basis of a primary succession resolved by CSR classification. Oikos, 112, 10-20. https://doi.org/10.1111/j.0030-1299.2006.14107.x.

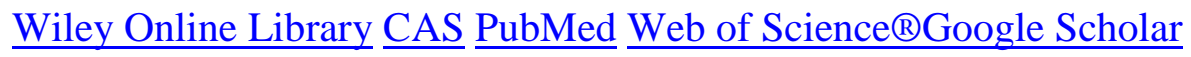

- Coelho, F. F., Capelo, C., \& Figueira, J. E. C. ( 2008). Seedlings and ramets recruitment in two rhizomatous species of rupestrian grasslands: Leiothrix curvifolia var. lanuginosa and Leiothrix crassifolia (Eriocaulaceae). Flora, 203, 152- 161. https://doi.org/10.1016/j.flora.2007.02.005.

\section{Crossref Web of Science®Google Scholar}

- Coelho, M. S., Carlos, P. P., Pinto, V. D., Meireles, A., Negreiros, D., Morellato, L. P. C., \& Fernandes, G. W. ( 2018). Connection between tree functional traits and environmental parameters in an archipelago of montane forests surrounded by rupestrian grasslands. Flora, 238, 51- 59. https://doi.org/10.1016/j.flora.2017.04.003.

\section{$\underline{\text { Crossref }} \underline{\text { Web of Science } ® \text { Google Scholar }}$}

- Coelho, M. S., Neves, F. S., Perillo, L. N., Morellato, L. P. C., \& Fernandes, G. W. ( 2018). Forest archipelagos: A natural model of metacommunity under the threat of fire. Flora, 238, 244- 249. https://doi.org/10.1016/j.flora.2017.03.013.

\section{$\underline{\text { Crossref }} \underline{\text { Web of Science } ® G o o g l e ~ S c h o l a r ~}$}

- Coelho, M. S., Fernandes, G. W., Pacheco, P., Diniz, V., Meireles, A., Santos, R. M., ... Negreiros, D. ( 2016). Archipelago of montane forests surrounded by rupestrian grasslands: New insights and perspectives. In G. W. Fernandes (Ed.), Ecology and conservation of mountaintop grasslands in Brazil (pp. 129- 156). Cham: Springer International Publishing. 


\section{CrossrefGoogle Scholar}

- Cornelissen, J. H. C. ( 1999). A triangular relationship between leaf size and seed size among woody species: Allometry, ontogeny, ecology and taxonomy. Oecologia, 118, 248- 255. https://doi.org/10.1007/s004420050725.

\section{$\underline{\text { Wiley Online Library CAS PubMed Web of Science }{ }^{\circledR} \text { Google Scholar }}$}

- Cunningham, S. A. ( 1997). The effect of light environment, leaf area, and stored carbohydrates on inflorescence production by a rain forest understory palm.

Oecologia, 111, 36- 44. https://doi.org/10.1007/s004420050205.

\section{$\underline{\text { Crossref PubMed Web of Science } ₫ \text { Google Scholar }}$}

- $\quad$ Dayrell, R. L. C., Arruda, A. J., Pierce, S., Negreiros, D., Meyer, P. B., Lambers, H., \& Silveira, F. A. O. ( 2018). Data from: Ontogenetic shifts in plant ecological strategies. Figshare. https://doi.org/10.6084/m9.figshare.7097969.

\section{$\underline{\text { Google Scholar }}$}

- Díaz, S., Kattge, J., Cornelissen, J. H. C., Wright, I. J., Lavorel, S., Dray, S., ... Gorné, L. D. ( 2016). The global spectrum of plant form and function. Nature, 529, 167- 171. https://doi.org/10.1038/nature16489.

\section{$\underline{\text { Crossref }} \underline{\text { CAS }} \underline{\text { PubMed Web of Science } ₫ \text { Google Scholar }}$}

- Echternacht, L., Sano, P. T., Trovó, M., \& Dubuisson, J. Y. ( 2011). Phylogenetic analysis of the Brazilian microendemic Paepalanthus subgenus Xeractis (Eriocaulaceae) inferred from morphology. Botanical Journal of the Linnean Society, 167, 137-152. https://doi.org/10.1111/j.1095-8339.2011.01170.x.

$\underline{\text { Wiley Online Library Web of Science } ® \text { Google Scholar }}$

- Fox, J. ( 2003). Effect Displays in R for Generalised Linear Models. Journal of Statistical Software, 8, 1-27. https://doi.org/10.18637/jss.v008.i15

\section{$\underline{\text { Crossref }} \underline{\text { Web of Science } ® G o o g l e ~ S c h o l a r ~}$}

- Gatsuk, L. E., Smirnova, O. V., Vorontzova, L. I., Zaugolnova, L. B. L., ... Zhukova, L. A. ( 1980). Age states of plants of various growth forms: A review. Journal of Ecology, 68, 675- 696. https://doi.org/10.2307/2259429.

\section{$\underline{\text { Crossref Web of Science }{ }^{\circledR G o o g l e ~ S c h o l a r ~}}$}

- Givnish, T. J. ( 1987). Comparative studies of leaf form: Assessing the relative roles of selective pressures and phylogenetic constraints. New Phytologist, 106, 131- 160. https://doi.org/10.1111/j.1469-8137.1987.tb04687.x. 
- González-Varo, J. P., \& Traveset, A. ( 2016). The labile limits of forbidden interactions. Trends in Ecology and Evolution, 31, 700- 710.

https://doi.org/10.1016/j.tree.2016.06.009.

\section{$\underline{\text { Crossref PubMed Web of Science®Google Scholar }}$}

- Grime, J. ( 1977). Evidence for the existence of three primary strategies in plants and its relevance to ecological and evolutionary theory. American Naturalist, 111, 11691194. https://doi.org/10.1086/283244.

\section{$\underline{\text { Crossref }} \underline{\text { CAS PubMed Web of Science®Google Scholar }}$}

- Grime, J. P., \& Pierce, S. ( 2012). The evolutionary strategies that shape ecosystems ( 1st ed.). Chichester: John Wiley \& Sons. https://doi.org/10.1002/9781118223246.

\section{Wiley Online LibraryGoogle Scholar}

- Grime, J. P., Thompson, K., Hunt, R., Hodgson, J. G., Cornelissen, J. H. C., Rorison, I. H., ... Whitehouse, J. ( 1997). Integrated screening validates primary axes of specialisation in plants. Oikos, 79, 259-281. https://doi.org/10.2307/3546011.

Wiley Online Library Web of Science®Google Scholar

- Grubb, P. J. ( 1977). The maintenance of species-richness in plant communities: The importance of the regeneration niche. Biological Reviews, 52, 107- 145. https://doi.org/10.1111/j.1469-185X.1977.tb01347.x.

\section{$\underline{\text { Wiley Online Library Web of Science }{ }^{\circledR G o o g l e ~ S c h o l a r ~}}$}

- Hallett, L. M., Standish, R. J., Jonson, J., \& Hobbs, R. J. ( 2014). Seedling emergence and summer survival after direct seeding for woodland restoration on old fields in south-western Australia. Ecological Management and Restoration, 15, 140- 146. https://doi.org/10.1111/emr.12110.

\section{$\underline{\text { Wiley Online Library Web of Science®Google Scholar }}$}

- Hamilton, N. ( 2017). R Package, "ggtern", version 2.2.1. Retrieved from https://cran.r-project.org/web/packages/ggtern/ggtern.pdf

\section{$\underline{\text { Google Scholar }}$}

- Harms, K. E., \& Dalling, J. W. ( 1997). Damage and herbivory tolerance through resprouting as an advantage of large seed size in tropical trees and lianas. Journal of Tropical Ecology, 13, 617-621. https://doi.org/10.1017/S0266467400010750.

\section{$\underline{\text { Crossref PubMed Web of Science }{ }^{\circledR G o o g l e ~ S c h o l a r ~}}$}

- Ishida, A., Yazaki, K., \& Hoe, A. L. ( 2005). Ontogenetic transition of leaf physiology and anatomy from seedlings to mature trees of a rain forest pioneer tree, Macaranga gigantea. Tree Physiology, 25, 513- 522. https://doi.org/10.1093/treephys/25.5.513. 
$\underline{\text { Crossref PubMed Web of Science®Google Scholar }}$

- Jung, V., Violle, C., Mondy, C., Hoffmann, L., \& Muller, S. ( 2010). Intraspecific variability and trait-based community assembly. Journal of Ecology, 98, 1134- 1140. https://doi.org/10.1111/j.1365-2745.2010.01687.x.

$\underline{\text { Wiley Online Library Web of Science®Google Scholar }}$

- Kembel, S. W., Cowan, P. D., Helmus, M. R., Cornwell, W. K., Morlon, H., Ackerly, D. D., ... Webb, C. O. ( 2010). Picante: R tools for integrating phylogenies and ecology. Bioinformatics, 26, 1463- 1464.

https://doi.org/10.1093/bioinformatics/btq166.

$\underline{\text { Crossref }} \underline{\text { CAS PubMed Web of Science®Google Scholar }}$

- Kitajima, K., Cordero, R. A., \& Wright, S. J. ( 2013). Leaf life span spectrum of tropical woody seedlings: Effects of light and ontogeny and consequences for survival. Annals of Botany, 112, 685- 699. https://doi.org/10.1093/aob/mct036.

$\underline{\text { Crossref PubMed Web of Science®Google Scholar }}$

- Lambers, H., \& Poorter, H. ( 1992). Inherent variation in growth rate between higher plants: A search for physiological causes and ecological consequences. Advances in Ecological Research, 23, 187-261. https://doi.org/10.1016/S0065-2504(03)34004-8.

\section{$\underline{\text { Crossref }} \underline{\text { CAS }} \underline{\text { Web of Science } ® \text { Google Scholar }}$}

- Lambers, H., Poorter, H., \& Vuuren, M. M. I. ( 1998). Inherent variation in plant growth. Physiological mechanisms and ecological consequences. Leiden: Backhuys.

\section{$\underline{\text { Google Scholar }}$}

- Larson, J. E., \& Funk, J. L. ( 2016). Regeneration: An overlooked aspect of trait-based plant community assembly models. Journal of Ecology, 104, 1284- 1298.

https://doi.org/10.1111/1365-2745.12613.

\section{$\underline{\text { Wiley Online Library Web of Science®Google Scholar }}$}

- Lasky, J. R., Bachelot, B., Muscarella, R., Schwartz, N., Forero-Montaña, J., Nytch, C. J., Uriarte, M. ( 2015). Ontogenetic shifts in trait-mediated mechanisms of plant community assembly. Ecology, 96, 2157-2169. https://doi.org/10.1890/14-1809.1.

$\underline{\text { Wiley Online Library PubMed Web of Science®Google Scholar }}$

- Li, Y., \& Shipley, B. ( 2017). An experimental test of CSR theory using a globally calibrated ordination method. PLoS One, 12, e0175404. https://doi.org/10.1371/journal.pone.0175404.

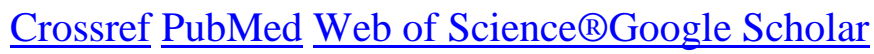


- Mason, C. M., Goolsby, E. W., Humphreys, D. P., \& Donovan, L. A. ( 2016).

Phylogenetic structural equation modelling reveals no need for an "origin" of the leaf economics spectrum. Ecology Letters, 19, 54- 61. https://doi.org/10.1111/ele.12542.

$\underline{\text { Wiley Online Library } \underline{\text { PubMed Web of Science }} \underline{\circledR} \text { Google Scholar }}$

- Mason, C. M., McGaughey, S. E., \& Donovan, L. A. ( 2013). Ontogeny strongly and differentially alters leaf economic and other key traits in three diverse Helianthus species. Journal of Experimental Botany, 64, 4089- 4099. https://doi.org/10.1093/jxb/ert249.

$\underline{\text { Crossref }} \underline{\text { CAS PubMed }} \underline{\text { Web of Science }{ }^{\circledR G o o g l e ~ S c h o l a r ~}}$

- May, R.-L., Warner, S., \& Wingler, A. ( 2017). Classification of intra-specific variation in plant functional strategies reveals adaptation to climate. Annals of Botany, 119, 1343-1352. https://doi.org/10.1093/aob/mcx031.

\section{$\underline{\text { Crossref PubMed Web of Science }{ }^{\circledR G o o g l e ~ S c h o l a r ~}}$}

- Metz, M. R. ( 2012). Does habitat specialization by seedlings contribute to the high diversity of a lowland rain forest? Journal of Ecology, 100, 969- 979. https://doi.org/10.1111/j.1365-2745.2012.01972.x.

Wiley Online Library Web of Science®Google Scholar

- Milberg, P., \& Lamont, B. B. ( 1997). Seed/cotyledon size and nutrient content play a major role in early performance of species on nutrient-poor soils. New Phytologist, 137, 665-672. https://doi.org/10.1046/j.1469-8137.1997.00870.x.

Wiley Online Library Web of Science®Google Scholar

- Moles, A. T., \& Westoby, M. ( 2004). What do seedlings die from and what are the implications for evolution of seed size? Oikos, 106, 193- 199.

https://doi.org/10.1111/j.0030-1299.2004.13101.x.

\section{$\underline{\text { Wiley Online Library Web of Science }{ }^{\circledR G o o g l e ~ S c h o l a r ~}}$}

- Münkemüller, T., Lavergne, S., Bzeznik, B., Dray, S., Jombart, T., Schiffers, K., \& Thuiller, W. (2012). How to measure and test phylogenetic signal. Methods in Ecology and Evolution, 3, 743- 756. https://doi.org/10.1111/j.2041210X.2012.00196.x.

Wiley Online Library Web of Science®Google Scholar

- Negreiros, D., Fernandes, G. W., Efremova, A. A., Stradic, S., \& Neves, A. C. O. ( 2016). Growth-survival trade-off in shrub saplings from Neotropical mountain grasslands. South African Journal of Botany, 106, 17- 22. https://doi.org/10.1016/j.sajb.2016.05.015.

$\underline{\text { Crossref }} \underline{\text { Web of Science } ® G o o g l e ~ S c h o l a r ~}$ 
- Negreiros, D., Stradic, S., Fernandes, G. W., \& Rennó, H. C. ( 2014). CSR analysis of plant functional types in highly diverse tropical grasslands of harsh environments. Plant Ecology, 215, 379- 388. https://doi.org/10.1007/s11258-014-0302-6.

\section{$\underline{\text { Crossref }} \underline{\text { Web of Science } ® G o o g l e ~ S c h o l a r ~}$}

- $\quad$ Oliveira, R. S., Galvão, H. C., Campos, M. C. R., Eller, C. B., Pearse, S. J., \& Lambers, H. ( 2015). Mineral nutrition of campos rupestres plant species on contrasting nutrient-impoverished soil types. New Phytologist, 205, 1183- 1194. https://doi.org/10.1111/nph.13175.

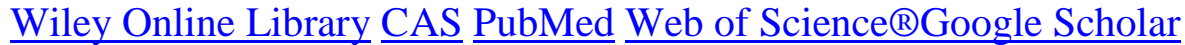

- Oñate, M., \& Munné-Bosch, S. ( 2009). Influence of plant maturity, shoot reproduction and sex on vegetative growth in the dioecious plant Urtica dioica. Annals of Botany, 104, 945-956. https://doi.org/10.1093/aob/mcp176.

\section{$\underline{\text { Crossref PubMed Web of Science }{ }^{\circledR G o o g l e ~ S c h o l a r ~}}$}

- Paine, C. E. T., Amissah, L., Auge, H., Baraloto, C., Baruffol, M., Bourland, N., ... Hector, A. ( 2015). Globally, functional traits are weak predictors of juvenile tree growth, and we do not know why. Journal of Ecology, 103, 978-989. https://doi.org/10.1111/1365-2745.12401.

\section{$\underline{\text { Wiley Online Library Web of Science } ® \text { Google Scholar }}$}

- Parkhurst, D. F., \& Loucks, O. L. ( 1972). Optimal leaf size in relation to environment. Journal of Ecology, 60, 505- 537. https://doi.org/10.2307/2258359.

\section{$\underline{\text { Wiley Online Library Web of Science®Google Scholar }}$}

- Pérez-Harguindeguy, N., Díaz, S., Garnier, E., Lavorel, S., Poorter, H., Jaureguiberry, P., ... Cornelissen, J. H. C. ( 2013). New handbook for standardized measurement of plant functional traits worldwide. Australian Journal of Botany, 61, 167- 234. https://doi.org/10.1071/BT12225.

\section{$\underline{\text { Crossref }} \underline{\text { Web of Science } ® \text { Google Scholar }}$}

- Pierce, S., Brusa, G., Vagge, I., \& Cerabolini, B. E. L. ( 2013). Allocating CSR plant functional types: The use of leaf economics and size traits to classify woody and herbaceous vascular plants. Functional Ecology, 27, 1002- 1010. https://doi.org/10.1111/1365-2435.12095.

\section{$\underline{\text { Wiley Online Library Web of Science }{ }^{\circledR G o o g l e ~ S c h o l a r ~}}$}

- $\quad$ Pierce, S., Negreiros, D., Cerabolini, B. E. L., Kattge, J., Díaz, S., Kleyer, M., ... Tampucci, D. ( 2017). A global method for calculating plant CSR ecological strategies applied across biomes world-wide. Functional Ecology, 31, 444- 457. https://doi.org/10.1111/1365-2435.12722. 
$\underline{\text { Wiley Online Library Web of Science®Google Scholar }}$

- Pierce, S., Vagge, I., Brusa, G., \& Cerabolini, B. E. L. ( 2014). The intimacy between sexual traits and Grime's CSR strategies for orchids coexisting in semi-natural calcareous grassland at the Olive Lawn. Plant Ecology, 215, 495- 505. https://doi.org/10.1007/s11258-014-0318-y.

\section{$\underline{\text { Crossref Web of Science } ® \text { Google Scholar }}$}

- Pinheiro, J. C., \& Bates, D. M. ( 2000). Extending the basic linear mixed-effects model. In J. C. Pinheiro \& D. M. Bates (Eds.), Mixed-effects models in S and S-PLUS (pp. 201-270). New York, NY: Springer-Verlag.

\section{CrossrefGoogle Scholar}

- Pinheiro, J., Bates, D., DebRoy, S., Sarkar, D., Heisterkamp, S., \& VanWilligen, B. ( 2017). Package "nlme": Linear and nonlinear mixed effects models, version 3.1-131. Retrieved from https://cran.r-project.org/web/packages/nlme/nlme.pdf

\section{$\underline{\text { Google Scholar }}$}

- Poorter, L. ( 2007). Are species adapted to their regeneration niche, adult niche, or both? American Naturalist, 169, 433-442. https://doi.org/10.1086/512045.

\section{$\underline{\text { Crossref PubMed Web of Science }{ }^{\circledR G o o g l e ~ S c h o l a r ~}}$}

- Poorter, L., \& Bongers, F. ( 2006). Leaf traits are good predictors of plant performance across 53 rain forest species. Ecology, 87, 1733- 1743. https://doi.org/10.1890/0012-9658(2006)87[1733:LTAGPO]2.0.CO;2.

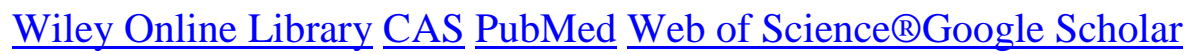

- R Development Core Team ( 2017). R: A language and environment for statistical computing. Vienna: Foundation for Statistical Computing. Retrieved from https://www.rproject.org

\section{$\underline{\text { Google Scholar }}$}

- Reich, P. B. ( 2014). The world-wide 'fast-slow' plant economics spectrum: A traits manifesto. Journal of Ecology, 102, 275-301. https://doi.org/10.1111/13652745.12211.

$\underline{\text { Wiley Online Library Web of Science®Google Scholar }}$

- Revelle, M. W. ( 2017). R package "psych", version 1.7.8. Retrieved from https://personality-project.org/r/psych

$\underline{\text { Google Scholar }}$ 
- Rosado, B. H. P., \& Mattos, E. A. ( 2017). On the relative importance of CSR ecological strategies and integrative traits to explain species dominance at local scales. Functional Ecology, 31, 1969- 1974. https://doi.org/10.1111/1365-2435.12894.

$\underline{\text { Wiley Online Library Web of Science }{ }^{\circledR G o o g l e ~ S c h o l a r ~}}$

- Silveira, F. A. O., Negreiros, D., Barbosa, N. P. U., Buisson, E., Carmo, F. F., Carstensen, D. W., ... Lambers, H. ( 2016). Ecology and evolution of plant diversity in the endangered campo rupestre: A neglected conservation priority. Plant and Soil, 403, 129- 152. https://doi.org/10.1007/s11104-015-2637-8.

\section{$\underline{\text { Crossref }} \underline{\text { CAS Web of Science } ® \text { Google Scholar }}$}

- Stearns, S. C. ( 1976). Life-history tactics: A review of the ideas. Quarterly Review of Biology, 51, 3- 47. https://doi.org/10.1086/409052.

\section{$\underline{\text { Crossref }} \underline{\text { CAS PubMed Web of Science®Google Scholar }}$}

- Stock, W., Pate, J., Kuo, J., \& Hansen, A. ( 1989). Resource control of seed set in Banksia laricina C. Gardner (Proteaceae). Functional Ecology, 3, 453- 460. https://doi.org/10.2307/2389619.

\section{Crossref Web of Science®Google Scholar}

- Thomas, S. C. ( 2011). Age-related changes in tree growth and functional biology: The role of reproduction. In F. C. Meinzer, B. Lachenbruch, \& T. E. Dawson (Eds.), Sizeand Age-Related Changes in Tree Structure and Function (pp. 33- 64). Dordrecht: Springer. https://doi.org/10.1007/978-94-007-1242-3_2.

\section{$\underline{\text { Crossref }} \underline{\text { Web of Science } ® \text { Google Scholar }}$}

- Valente, E. L. ( 2009). Relações solo-vegetação no parque nacional da Serra do Cipó, Espinhaço Meridional. PhD thesis. Viçosa, Brazil: Universidade Federal de Viçosa. Retrieved from http://locus.ufv.br/handle/123456789/1594

\section{$\underline{\text { Google Scholar }}$}

- Violle, C., Enquist, B. J., McGill, B. J., Jiang, L., Albert, C. H., Hulshof, C., ... Messier, J. ( 2012). The return of the variance: Intraspecific variability in community ecology. Trends in Ecology and Evolution, 27, 244- 252. https://doi.org/10.1016/j.tree.2011.11.014.

\section{$\underline{\text { Crossref PubMed Web of Science®Google Scholar }}$}

- Webb, C. O., Ackerly, D. D., \& Kembel, S. W. ( 2008). Phylocom: Software for the analysis of phylogenetic community structure and trait evolution. Bioinformatics, 24, 2098-2100. https://doi.org/10.1093/bioinformatics/btn358.

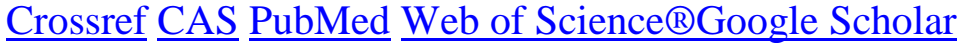


- Wickham, H. ( 2016). ggplot2: Elegant Graphics for Data Analysis. New York, NY: Springer-Verlag. Retrieved from https://cran.rproject.org/web/packages/ggplot2/index.html

\section{$\underline{\text { CrossrefGoogle Scholar }}$}

- Wright, I. J., Groom, P. K., Lamont, B. B., Poot, P., Prior, L. D., Reich, P. B., ... Westoby, M. ( 2004). Leaf trait relationships in Australian plant species. Functional Plant Biology, 31, 551- 558. https://doi.org/10.1071/FP03212.

\section{$\underline{\text { Crossref }} \underline{\text { Web of Science } ® G o o g l e ~ S c h o l a r ~}$}

- Zalamea, P., Turner, B. L., Winter, K., Jones, F. A., Sarmiento, C., \& Dalling, J. W. ( 2016). Seedling growth responses to phosphorus reflect adult distribution patterns of tropical trees. New Phytologist, 212, 400- 408. https://doi.org/10.1111/nph.14045.

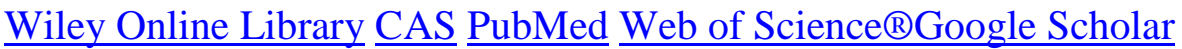

- Zuur, A. F., Ieno, E. N., Walker, N., Saveliev, A. A., \& Smith, G. M. ( 2009). Mixed effects models and extensions in ecology with R, Vol. 53. New York, NY: Springer. https://doi.org/10.1007/978-0-387-87458-6.

CrossrefGoogle Scholar 